\title{
ARTICLE
}

\section{Treating Water: \\ Engineering and the Denial of Indigenous Water Rights}

\author{
Travis Hnidan \\ Science and Technology Studies, York University, hnidan@yorku.ca
}

In 2011, the Department of Aboriginal Affairs and Northern Development Canada released the National Assessment of First Nations Water and Wastewater Systems as prepared by Neegan Burnside Ltd. This assessment has been largely used by government, media, and Indigenous groups to point to the decrepit state of water and wastewater systems on First Nations reserves across the country, and to advance Senate Government Bill S-8 that seeks to improve conditions in these communities. In this article, I provide a critique of the National Assessment to outline its underlying assimilationist ideology and to demonstrate how technical engineering documents can have political implications. Power is wielded by technocratic discourses like engineering and, in this case, respect for Indigenous rights and sovereignty are at stake when so-called "objective" practices reflect institutional power.

KEYWORDS: First Nations, Canada, water, water rights, wastewater, engineering

\section{HEADWATERS}

Roxane and I have been given the value of Wisdom. We have been asked to synthesize a statement relating Wisdom to water. We are drafting part of a manifesto around the seven values (Courage, Respect, Humility, Truth, Honesty, Love, and Wisdom). Our statement will be combined with the preceding six, drafted by other pairings, to form the manifesto. This is part of a Waterlution ${ }^{1}$ workshop called "Our Water is Our Life: A dialogue and action weekend to look at the future of water for Aboriginal communities." As a settler water resources engineering graduate student conducting research with a First Nations community, this event interested me.

Roxane introduces herself: she is a Blackfoot woman and Masters in Education. I introduce myself. We don't really know how to begin addressing Wisdom, so Roxane shares a story of a neardrowning experience she had as a child. I also have a near-drowning story from childhood. We decide that this shared experience may be a good place to elaborate and while I'm still trying to think about how these experiences could possibly relate to wisdom, Roxane offers a quick explanation: water has wisdom and it imparts wisdom to us as we interact with it. Through her near-drowning experience, water shared its wisdom with Roxane and she became wiser for it.

I feel a little taken aback by this. Water doesn't have wisdom. Surely one can become wiser by interacting with water, but water is not deliberately, consciously teaching us. Water's

\footnotetext{
1 Waterlution is a registered non-profit corporation that promotes awareness and provides opportunities for collaborative, long-term, and inclusive water management.
} 
consciousness had been mentioned in the workshop the day previous, along with a story of how praying for water can ensure clean, healthy water. Coming from the Western tradition, I'm not familiar with this perspective but I do want to be sensitive to it, so I decide to explore Roxane's analysis a bit in the hope of at least coming to understand it better.

I ask Roxane if she believes that praying for water makes it or keeps it healthy. She says that she does. I definitely don't understand this. How could praying possibly impact water quality? I tell Roxane that it's impossible for me to think of water as being conscious or that by praying for water, that water can be fundamentally changed.

Contemporary Western thinkers have considered similar beliefs. Actor-network theory, for example, attempts to decenter humans in technoscience and consider the agency of non-humans (Latour, 1987). Using such a framework can reveal how non-human entities (water, microorganisms, electricity, etc.) behave as agents, acting and reacting in their worlds. Certainly this school of thought could provide some insight on how Western philosophy-and my perspectivecould theorize non-human experience. I hesitate to use this framework, however, when addressing an Indigenous person's understanding of an Indigenous issue. Zoe Todd (2014), a Métis scholar, explains some of the problems in this Western approach (along with further resources). Vanessa Watts (2013), Mohawk and Anishnaabe, picks up a critique of Latour's work specifically and reveals some fundamental distinctions between Actor-network theory and Indigenous ontologies. Sarah Hunt (2014), a Kwakwaka'wakw scholar, further demonstrates ontological differences between Indigenous and Western philosophies. So back to Roxane.

After some more conversation and patience on the part of Roxane, I consider: a water user, someone who is consuming water, would probably change their behaviour if they believed that water was conscious or if they prayed before using it. I am reminded of a talk by Winona LaDuke, an Anishinaabe author and activist, who proclaimed, when discussing wastewater, how can water be waste!? If Western society viewed water as a conscious entity, or something worthy of more respect, a lot of water use behaviours would change, like using it for dilution or as a waste transport. It follows that one would also be more conservative with water use. If there are concerns about water scarcity, wouldn't it be much simpler if water use were a less ubiquitous activity, one that involved respect? Folks would conserve more water. There would be fewer issues with water quality as waste management practices would require other solutions.

I try to relate these ideas to Roxane. I can explain the value in treating water as though it were conscious, an entity worthy of respect. I don't see it as conscious myself at this point, but I try to rationalize the utility of thinking in this way. I ask Roxane if water's consciousness can be understood as a resource management tool, if these ideas agree, if we are talking about the same thing. She says we are talking about the same thing. While I am still grappling with what it means to think about water as conscious, I can at least accept it as part of Roxane's world and move on with the exercise. We write our statement on Wisdom.

\section{SOURCE WATERS}

This story is one of my first encounters with a directly conflicting worldview in my field of study. And while at the time I was still rationalizing what Roxane had said to mean something other than what she had actually said-water is conscious, praying for water is good, water is wise, water teaches us-it was an important step for me in better understanding my worldview and how it has been shaped by (Western) engineering discourse. Since the time of this workshop I've been curious about ways in which engineering epistemology disagrees with Indigenous epistemologies and if this could be related to the "infrastructure crisis" plaguing First Nations across Canada. 
Knowledge, in Western academic thought, is inherently political and, as a result, can be oppressive (Potts \& Brown, 2005, p. 261). I wonder, then, about the knowledge and thus political ideologies served by engineering as a discipline that espouses objectivity and disinterest (Leydens, Lucena, \& Schneider, 2012, p. 71). In other words, what knowledges are subjugated by privileging an engineer's approach to a problem over another's? Foucault explains how criticism can reveal these subjugated knowledges that have been hidden or masked by dominant ones $(1980$, p. 82). I am interested in applying criticism to engineering as a dominant form of knowledge in Western culture.

In Winona LaDuke's (1999) work, All Our Relations: Native Struggles for Land and Life, she touches on this apparent epistemological conflict between the technological (Western knowledges) and the spiritual (Indigenous knowledges):

The choice between the technological and the spiritual will be based on both collective and individual decisions, both simple and complex. For just as life itself is a complex web of relationships and organisms, so is the fabric of a community and a culture that chooses its future. Either way, according to Indigenous worldviews, there is no easy fix, no technological miracle. (p. 200)

In the article that follows, I provide a close-reading analysis of the National Assessment of First Nations Water and Wastewater Systems: National Roll-Up Report (hereinafter referred to as the National Assessment) and its explanatory materials to explore how a technical or objective approach to assessing/improving quality of water-and thus, life-on-reserve serves to epistemologically limit and control Indigenous rights and sovereignty. First, I contextualize the National Assessment and its significance as source material. Second, I analyze how the engineering and risk frameworks of the National Assessment describe water systems and the consequent limitations. Third, I elucidate how the National Assessment characterizes water and wastewater treatment plant operators as the site for risk, control, and legislation. Fourth, I demonstrate how the omission of (First Nations) people and governments from the National Assessment posits poor (waste)water servicing as a technical problem from which Indigenous communities are removed. Last, I restate the National Assessment's problematic colonial narrative and conclude by reflecting on how my perspective has changed throughout my studies and since first drafting this article, emphasizing the need for community-based decision making.

In 2009, the Department of Aboriginal Affairs and Northern Development Canada (AANDC) ${ }^{2}$ retained Aboriginal majority-owned engineering consulting firm Neegan Burnside Ltd. to conduct the first cross-Canada evaluation of First Nations public and private water infrastructure. Two years later, on July 14, 2011, the National Assessment was released. The results were not promising. Hailed as "the largest and most rigorous assessment of its kind ever conducted in Canada" (AANDC, 2011d), this document classified 39 per cent of First Nations water systems as high overall risk of providing unsafe drinking water and 34 per cent as medium overall risk (Neegan Burnside Ltd., 2011, p. 16) - the implication being that improvements are necessary at an estimated cost of $\$ 1.08$ billion.

The day of the National Assessment's release, the Assembly of First Nations (AFN) responded, citing some of its results and the urgent need to improve water and wastewater systems (AFN, 2011). The House debate of Bill S-8 or the Safe Drinking Water for First Nations Act-which began less than two years later on November 1st, 2012-opened with a statement citing results of the National Assessment (Open Parliament, 2014). Members of Parliament continued to cite the National Assessment results throughout Bill S-8's debate until it received Royal Assent in June 2013. News

2 Then known as Indian and Northern Affairs Canada (INAC). 
articles on water problems in First Nations communities have cited the National Assessment since its release and continue to do so. These actions point to the significance of this document and the relevance of its critique.

The analysis I present will draw primarily from the National Roll-up Report but as we are warned on the AANDC (2012) National Assessment webpage, "[t]he National Assessment results provide a substantial amount of information, much of which is fairly complicated and technical in nature. To help clarify the results and what they mean to First Nations, the Department has developed a series of informative fact sheets." Thus, the various Fact Sheets and other documents that accompany the report found on the AANDC website will provide further material for analysis. These documents include:

- Department's Response to the National Assessment of First Nations Water and Wastewater Systems (Department's Response) (AANDC, 2011a),

- Fact Sheet - Risk Assessment of Water and Wastewater Systems in First Nations Communities (Risk Fact Sheet) (AANDC, 2011b),

- Fact Sheet - The Results of the National Assessment of First Nations Water and Wastewater Systems (Results Fact Sheet) (AANDC, 2011c),

- Fact Sheet - Understanding the Results of the National Assessment (Understanding Fact Sheet) (AANDC, 2011d), and

- Chronology - Water (AANDC, 2013) ${ }^{3}$

My critique shares much in structure with some of Michael Mascarenhas's arguments presented in his work, Where the Waters Divide: Neoliberalism, White Privilege, and Environmental Racism in Canada (2012), which I use to support my analysis. I also draw on Ulrich Beck's Risk Society (1992) to underscore the social construction and formation of risk measurement, in addition to Donna Haraway's "Situated Knowledges: The Science Question in Feminism and Privilege of Partial Perspective" (1988) and John Law's Aircraft Stories: Decentering the Object in Technoscience (2002) to critique technoscientific and engineering methodologies. Let's begin.

\section{WATER SYSTEMS}

It is apparent how the assessment process itself-the federal government entering First Nations communities to evaluate their water systems and wastewater systems-is a paternalistic exercise, disrespectful of First Nations sovereignty to choose to evaluate their own systems in their own ways. But within the National Assessment and accompanying materials are some more insidious modes of control.

One example is how risks of small water systems are compared to those of large systems, "[i]t was generally observed that the simpler the facility the more likely the facility was to have medium or high overall risk [...]. The simpler and small systems are often riskier as they are more likely to lack suitable treatment resources" (Neegan Burnside Ltd., 2011, p. 23). It is explained that risk increases as system size decreases and why a simpler, smaller system would be riskier: insufficient resources.

3 I focus on the National Roll-Up Report instead of any of the Regional Roll-Up Reports because the results of the National Assessment as a whole were taken as evidence for the dire state of (waste)water servicing on First Nations reserves and as justification for subsequent legislation (Bill S-8). Plus, the more specific regional reports use the same methodology and communicate the same findings as the national one, simply on a regional scale with more discrete analysis. To my knowledge, the regional reports have not been used to advance legislation nor have they been cited as ubiquitously as the National Assessment. 
Data presented in "Table 3.8 - Summary of Overall Risk Levels by Treatment Classification Water", which follows (see Figure 1), shows this relationship numerically between size (increasing "Level" number denotes increasing size) and risk.

Table 3.8 - Summary of Overall Risk Levels by Treatment Classification - Water
\begin{tabular}{|l|c|c|c|c|c|c|c|c|}
\hline $\begin{array}{c}\text { Overall } \\
\text { Risk Level }\end{array}$ & $\begin{array}{c}\text { Small } \\
\text { System }\end{array}$ & Level I & Level II & $\begin{array}{c}\text { Level } \\
\text { III }\end{array}$ & $\begin{array}{c}\text { Level } \\
\text { IV }\end{array}$ & MTA & None & Total \\
\hline High & 126 & 57 & 44 & 16 & 0 & 10 & 61 & $\mathbf{3 1 4}$ \\
\hline Medium & 31 & 65 & 96 & 24 & 0 & 45 & 17 & $\mathbf{2 7 8}$ \\
\hline Low & 23 & 25 & 48 & 16 & 1 & 97 & 5 & $\mathbf{2 1 5}$ \\
\hline Total & $\mathbf{1 8 0}$ & $\mathbf{1 4 7}$ & $\mathbf{1 8 8}$ & $\mathbf{5 6}$ & $\mathbf{1}$ & $\mathbf{1 5 2}$ & $\mathbf{8 3}$ & $\mathbf{8 0 7}$ \\
\hline
\end{tabular}

Figure 1. Screen Capture of Table 3.8 (Source: Neegan Burnside Ltd., 2011, p. 23)

The paragraph that follows in the National Assessment presents us with a similar comparison but for wastewater systems: "For wastewater treatment systems, it appears that a higher plant classification [a higher population served] is positively correlated with the incidence of a facility having a medium or high overall risk. MTA [Municipal Type Agreement] systems are the most likely to be low risk" (Neegan Burnside Ltd., 2011, p. 23). Here, no explanation is provided to clarify why this is the case, as was done for water systems before (lack of resources). There is no rationale presented to justify why the relationship between system size and system risk for wastewater systems is opposite of that for water systems. Surely small wastewater treatment systems lack resources to a similar degree as small water treatment systems. It seems odd then to provide a lack of resources as an explanation for water system risk without addressing how it affects wastewater system risk.

How this gap, or missing interpretation, is further communicated in the AANDC Understanding Fact Sheet is significant: "[ $t]$ he majority of high risk systems serve a small population. Water systems in remote communities are 2.5 times more likely to be high risk than low risk" (2011d). Here the risk results from water systems are used to describe all systems (both water and wastewater) even though the correlation between risk and population served (size) for wastewater systems is the inverse. This statement is then supported by a zone (remoteness) analysis of risk taken from the National Assessment. 49\% of Zone 4 (more remote) water systems are high risk and 19\% of Zone 4 water systems are low risk (Neegan Burnside Ltd., 2011, p. 19). By using these two data sets together (the zone-risk relationships and the size-risk relationship), the Understanding Fact Sheet suggests that small, remote systems (both water and wastewater) are more likely to be high risk.

Highlighting this connection between remoteness or smallness and risk marginalizes some communities by defining them as the site of risk while freeing other (more urban, accessible) communities of that risk. Critiquing risk measurement, sociologist Ulrich Beck describes how one is "afflicted by risk" and as such, risk is "ascribed by civilization" (1992, p. 23). Therefore, this devaluing of remote lifestyle in the National Assessment reflects a colonial ideology in which urban lifestyles are privileged. As Beck explains, there are always winners and losers in risk definition (1992, p. 23). What are shown to be objectively less risky (and more affordable) in the National Assessment are systems serving large populations near municipalities. By positing a smaller community as a dangerous way to live, the National Assessment leads one to believe that large social organizations are ideal. The stereotypical traditional First Nations "tribe" is risky, and the colonial industrialized city is safe. How does this sort of valuing allow First Nations to exercise sovereignty when certain ways of life are deemed costly or risky?

The National Assessment itself draws attention to this unbalanced evaluation: 
The risk evaluation system is currently not set up to evaluate certain situations such as the typical Municipal Type Agreement (MTA) system where the First Nation has an agreement with a nearby municipality to provide water or wastewater services, nor is it designed to assess the risk associated with communities that rely on individual servicing or houses with no servicing. (Neegan Burnside Ltd., 2011, p. 42)

Further, "[i]n general, it is assumed that MTA systems would have a lower overall risk than other systems because they operate in accordance with provincial legislation" (Neegan Burnside Ltd., 2011, p. 22). Again, there is a reason why a system shared with a municipality would have less risk, because "they operate in accordance with provincial legislation", but the National Assessment says that the "evaluation system is currently not set up to evaluate [...] the typical Municipal Type Agreement (MTA) system". What value is there in reporting the results of an evaluation which is not designed to evaluate the subject of interest? (And why is compliance assumed for water services under provincial legislation?) This critique applies similarly to "communities that rely on individual servicing or houses with no servicing" (Neegan Burnside Ltd., 2011, p. 42) (small, remote systems), which the National Assessment says cannot be properly evaluated using the current system. The results of the National Assessment are used to conclude that small, remote systems are risky and systems with Municipal Type Agreements are less risky although the National Assessment itself says it cannot properly evaluate either.

Moreover, this need to analyze data in a manner that uncovers national trends betrays another cultural bias of the National Assessment, and technoscience discourses more broadly: that of narrative continuity. John Law mentions engineers, and engineering texts, specifically, as story tellers of technology that display a "tendency to perform singularity and the concomitant tendency to marginalize multiplicity" (2002, pg. 76). Law explains that this tendency results in a bias against discontinuity, multiplicity, and "that which cannot be assimilated" (2002, pg. 76). So, for example, even though the relationships between (waste)water system risk and size cannot be entirely accounted for given the presented data in the National Assessment, "if we [engineers] cannot assimilate something, trace lines of similarity, explication, then somehow or other we failed. Even if the events present themselves as discontinuous. Broke up. Or multiple" (Law, 2002, pg. 76). The remedies put forth for risky (waste)water systems (money, legislation, operator certification) rely on this narrative singularity, as I explain later.

Second, as the explanation from the National Assessment for the correlation between size and risk explains, "smaller systems are often riskier as they are more likely to lack suitable treatment resources" (Neegan Burnside Ltd., 2011, p. 23). While it is apparent that a smaller system lacks resources, this explanation helps reinforce a purpose of the National Assessment: to emphasize the technical nature of the problem. A smaller or more remote system is missing access to physical resources regardless of the less tangible resources that exist in operator experience and local knowledge, for example.

Michael Mascarenhas specifically argues "how local contextualized knowledge is subordinated by technical 'credentialized' expertise" in water treatment on-reserve (2012, p. 18). Mascarenhas explains that the "prevalence of expertise functions to reduce societal problems" $(2012$, p. 18) to technical ones, removing "issues of power and equity" (2012, p. 19). Similarly, Donna Haraway, discussing the "science question" in feminism, argues that science and Western objectivity seek omniscient power by distancing themselves (the knowing subject) from everything (1988, p. 581). Haraway sees situated knowledge as a sort of feminist objectivity, where observers are responsible for their observations (1988, p. 583) and their enabling practices (1988, p. 587). Certainly localized knowledge is responsible to its localized context, a point to which I will return in the next section.

Mascarenhas shows that by introducing the requirement for treatment plant operators to hold valid operator's certificates in Ontario, the government effectively "rendered the majority of First 
Nations operators in the province as unqualified to operate their drinking water systems" (2012, p. 126). This type of legislation accomplished a similar feat as the National Assessment: a problem is created through definition and the means for addressing the problem lie in the hands of those who defined it. Without cooperation across groups of stakeholders involved in risk measurement (an unfortunate condition of the National Assessment), risk determination distintegrates into what Beck calls "definitional struggles" (1992, p. 29). By conducting the National Assessment, the problem of 39 per cent of First Nations water systems being high overall risk has been defined, paralleling how operators were defined to be unqualified in Ontario. Nothing has actually resulted from the exercise other than demonstrating that quality of life on First Nations reserves is unsuitable. The public has been informed about the resultant high risk (waste)water systems in First Nations communities and, for fear of seeming irresponsible, First Nations are expected to go through the appropriate funding and administrative procedures to address these problems (Mascarenhas, 2012, p. 130). This process again fails to allow First Nations to self-govern but also perpetuates an "infrastructure gap" whereby First Nations communities are defined as having deficient infrastructure by comparing their living standards to those of other Canadians (Mascarenhas, 2012, p. 5). Measuring risk inherently creates a universal, utopic norm for comparison-and risks exist as deviations from this "true" norm (Beck, 1992, p. 28)-urban settler Canadian society, in this case. First Nations communities must then seek financial support to meet protocols that are subsequently amended to show how deficiencies remain (Mascarenhas, 2012, p. 101). The very notion of development to certain standards, protocols, or guidelines, as Mascarenhas shows, is part of the neoliberal myth of development (2012, p. 105): it provides not only the mechanism for "improvement", but the goal of "improved". Seen in this light, the National Assessment reinforces colonial, assimilationist ideology.

\section{WATER OPERATORS}

A series of recommendations can be found at the end of the National Assessment including the "establishment of a regulatory framework for water and wastewater systems [...] approvals, operator certification, [and] water quality testing" (Neegan Burnside Ltd., 2011, p. 45). This recommendation and the results of the National Assessment at large were used to promote Bill S-8 or the Safe Drinking Water for First Nations Act.4 Bill S-8 was introduced less than a year after the release of the National Assessment and after much controversy during Idle No More, the bill became law. Among other First Nations (waste)water related issues, Bill S-8 grants the ability of government to create regulations on:

(a) the training and certification of operators of drinking water systems and waste water systems;

(b) the protection of sources of drinking water from contamination;

(c) the location, design, construction, modifications, maintenance, operation and decommissioning of drinking water systems (Senate of Canada, 2012)

"Regulations made under [Bill S-8] prevail over any laws or by-laws made by a First Nation to the extent of any conflict or inconsistency between them, unless those regulations provide otherwise" (Senate of Canada, 2012). Bill S-8 also allows regulations to "incorporate by reference laws of a province", pushing provincial laws onto First Nations. Despite assurances that "nothing in [Bill S-8] or the regulations is to be construed so as to abrogate or derogate from any existing Aboriginal or treaty rights [...] except to the extent necessary to ensure the safety of drinking water of First Nation lands" (Senate of Canada, 2012), the Canadian Bar Association found that the qualification of

${ }^{4}$ See Legislative Summary - Bill S-8: The Safe Drinking Water for First Nations Act, "1.9 National Assessment of First Nations Water and Wastewater Systems" (pp. 5-6) or visit the Open Parliament webpage for Bill S-8 (https://openparliament.ca/bills/41-1/S-8/?page=2) to read references to the National Assessment. 
"except to the extent necessary" "an explicit abrogation or derogation of existing Aboriginal or treaty rights pursuant to section 35 of the Constitution Act, 1982" (Craft, 2013, p. 2). The significance of Bill S-8's history is how its acceptance heavily relied on the results of the National Assessment and how these results were communicated further.

Specifically in the Department's Response, we find the following: "Operation and Maintenance $(0 \& M)$, operator qualification, and record keeping account for 60 per cent of the risk measured. This underscores the vital importance of having trained and certified operators for reducing risk and helping to ensure safe drinking water in First Nations communities" (AANDC, 2011a). Further, "design risk only accounts for 30 per cent of the risk identified in high risk systems" (AANDC, 2011a). These excerpts are significant because AANDC (2013) highlights these results in Chronology - Water:

July 14, 2011 Department releases independent National Assessment of First Nations Water and Wastewater systems. Report states the need for a water and wastewater regulatory regime and standards on-reserve. The [National] Assessment shows that the operation and maintenance, operator qualification, and record keeping account for 60 per cent of risk measured.

These were the only results of the National Assessment that are shared on Chronology - Water: the need for regulation (Bill S-8) and that operators/staff account for the majority of risk. The problem lies not only with the fact that these are the results highlighted by the Department, but that the calculation for "60 per cent of risk measured" is one entirely defined through the assessment process. Plus, it is used in an attempt to place the cause of risk squarely on those working in (waste)water treatment (mostly First Nations operators and administrative staff).

\section{Reviewing the Risk Fact Sheet,}

the overall system rank is calculated using a weighted value for each category as follows:

- water source and the wastewater effluent receiver (10 per cent)

- system's design (30 per cent)

- operation and maintenance (30 per cent)

- the level of training and certification of its operator (20 per cent)

- reporting and record keeping (10 per cent). (AANDC, 2011b)

"Operation and maintenance (O\&M), operator qualification, and record keeping account for 60 per cent of the risk measured" (2011a, AANDC) (quoted previously) because they are defined as accounting for that much risk in the calculation. The risk calculation defines operation and maintenance (30 per cent), operator qualification (20 per cent), record keeping (10 per cent) to account for a total of 60 per cent of risk measured $(30+10+20=60)$. By saying that these criteria account for 60 per cent of the risk, the Department suggests that this is a result of the National Assessment rather than the methodology used in conducting the National Assessment. One could just as easily conclude that the system's design, operation and maintenance, and water source account for 70 per cent of the risk measured and that operator qualification only accounts for 20 per cent of the risk identified in high risk systems, emphasizing an entirely different aspect of system risk.

The point here is that this particular interpretation of the risk assessment tool confirms its colonial bias. Beck identifies those scientific and legal professions and the mass media (like technical communications) that define risk as holding key social and political positions (1992, p. 23). Beck elaborates that since hazards escape direct human perception, they require "qualified expert judgement [...] to determine [them] objectively" (1992, p. 27). And since risk always uses an imaginary link between cause and effect, it is invisible; the implied causality is theoretical and thus, scientized (Beck, 1992, p. 28). In other words, the science of risk (understanding and evaluating an invisible force) is accessible only to experts and those experts are political agents. The tool itself- 
through the "objective" scientific power imbued in it-reflects and thus serves a political end. Returning to the document, the presentation of risk weights in the Department's Response suggests that these categories are the actual causes of risk. By saying "operation and maintenance, operator qualification, and record keeping account for 60 per cent of the risk measured", it makes operators and administrative staff the cause of risk. While the statement is strictly true (those particular aspects $d o$ account for 60 per cent of risk), its use to underscore "the vital importance of having trained and certified operators for reducing risk" (AANDC, 2011a) places the duty of risk reduction on operators. Mascarenhas explains that by shifting a social problem to a technical one, the victim is blamed for being incompetent (2012, p. 72). The symptom of degraded water quality is addressed as the problem rather than the cause: unsustainable relationships with the environment (Mascarenhas, 2012, p. 97). This is clearly demonstrated in the Risk Fact Sheet where water source (the actual quality and quantity of raw water available) only accounts for 10 per cent of the total risk weight. Undrinkable water from the environment and the consequent need for treatment are givens in this scenario rather than consequences of colonization/pollution.

Regardless of how treatment plant operators are characterized in other documents, in the National Assessment, "Operator" is actually the lowest contributor (pre-weight calculation) for risk in (waste)water systems as shown in "Figure 3.4 - Water: Risk Profile Based on Risk Components by Region" (Neegan Burnside Ltd., 2011, p. 18) (see Figure 2) and "Figure 3.6 - Wastewater: Risk Profile Based on Risk Component by Region" (Neegan Burnside Ltd., 2011, p. 21) (see Figure 3). The data collected for the National Assessment says that: "design risk is approximately 5.3 and operator risk is the lowest at 2.6" (Neegan Burnside Ltd., 2011, p. 16). This stands in direct opposition to how the "Department's Response" interprets the risk evaluation where operators were suggested as being the most significant contributors to risk.

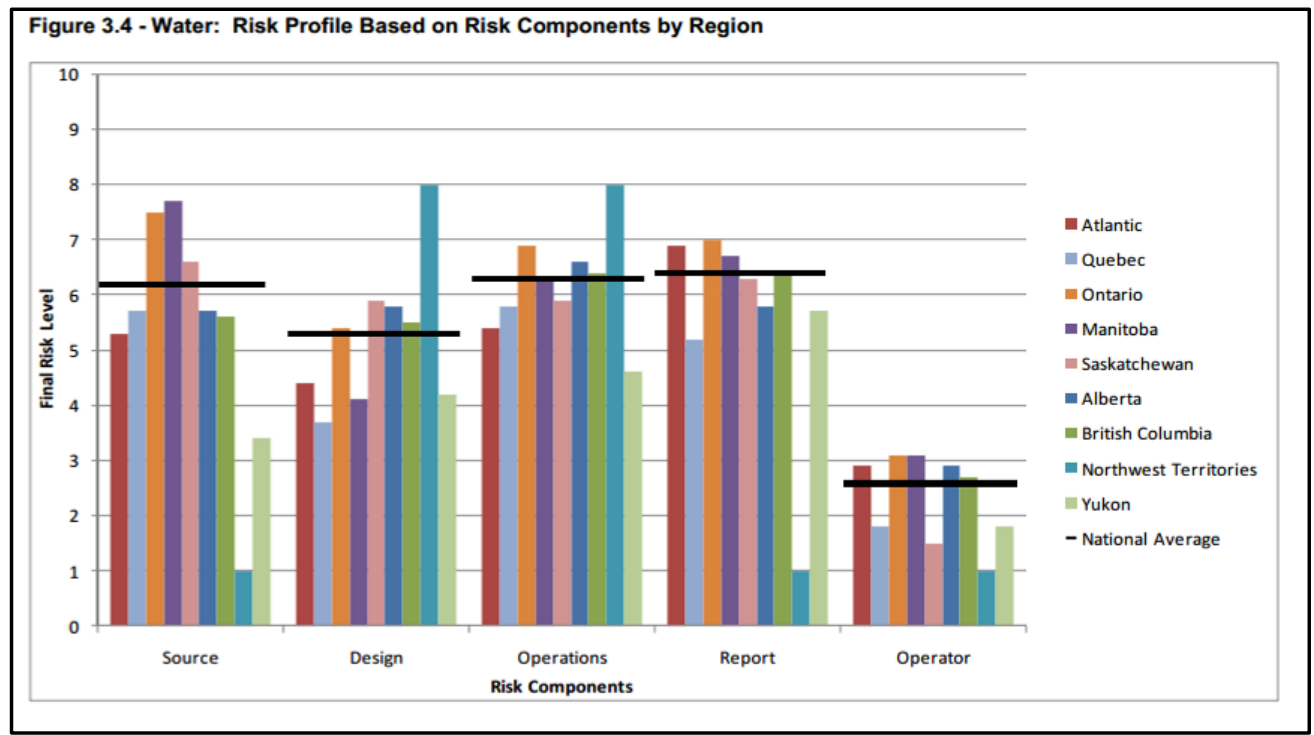

Figure 2. Screen Capture of Figure 3.4 (Source: Neegan Burnside Ltd., 2011, p. 18) 


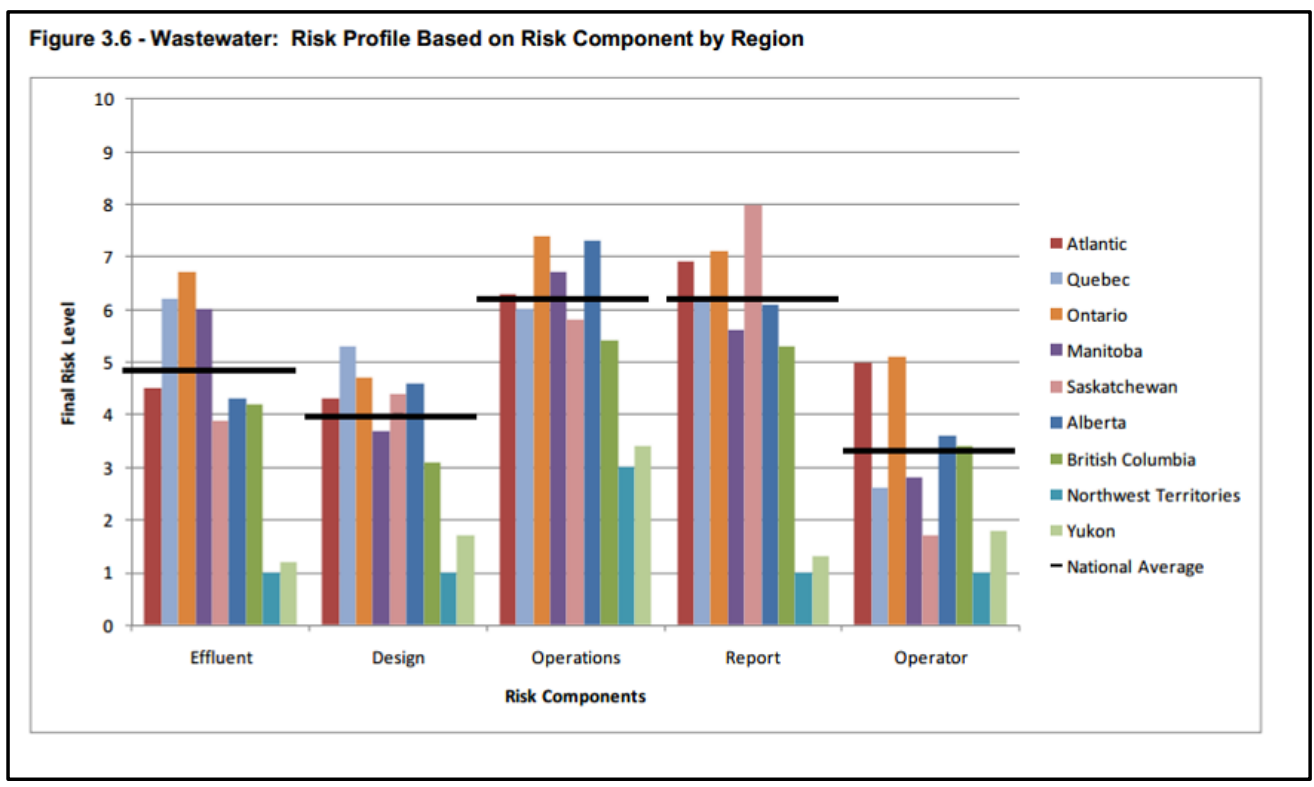

Figure 3 Screen Capture of Figure 3.6 (Source: Neegan Burnside Ltd., 2011, p. 21)

If design risk and source water risk were emphasized over operator risk, blame for poor (waste)water servicing would be shifted to other actors in the system. The federal government would certainly appear more culpable for providing inadequate resources for the necessary design of (waste)water treatment technologies on-reserve, while provincial governments would be scrutinized for their insufficient effluent discharge regulations to ensure safe water downstream of municipalities, industrial sites, and agricultural lands. By shifting the focus, and thus blame, for poor (waste)water servicing towards operators and away from colonial institutions, treatment operation becomes the role in need of improvement and subsequent control while poor environmental water quality and deficient technological design are accepted as normal.

Emphasizing the need to improve (waste)water treatment plant operation provides additional concerns for First Nations communities. In Where the Waters Divide, Mascarenhas, when discussing treatment plant operator certification, points out that "First Nations fear that in recognizing these new technologies of [the Canadian federal] government they may further discredit their own oral tradition of mentorship" (2012, p. 129). Not only may the role of (certified treatment plant operator) expertise be in disagreement with First Nations cultures and epistemologies, but its very creation is the "government's response to delinquent investment in drinking water conditions in First Nations communities" (Mascarenhas, 2012, p. 127). Water has been defined as a "technical problem in need of expertise. [...] This translation of racial programs [...] into technical discourses has been a key strategy of neoliberal governments where substantive authority of expertise and market logics are enrolled into the apparatus of political rule" (Mascarenhas, 2012, p. 127).

If operator expertise is the legitimate concern of AANDC as a result of the National Assessment, surely local, contextualized, first-hand knowledge would be valued in contributing to expertise over, say, a certificate in water treatment plant operation. As Mascarenhas concludes from interviewing treatment plant operators:

the daily operation of a First Nations' water treatment plant requires a level of sophistication and dedication that is simply unparalleled. First Nations operators not only require a welldeveloped understanding of their treatment facility, but also are knowledgeable about local land use practices that might adversely impact the quality of their water supply. (2012, p. 126) 
What Haraway describes as the "god trick" of technoscience, the process of "seeing everything from nowhere" (1988, p. 581), is applied in this scenario where credentialization ("objective" knowledge) supersedes localization ("situated" knowledge). Law elaborates on his explanation of narrative bias in technoscience: that in "telling stories and making connections", context "is desegregated and colonized" (2002, p. 78). Rather than considering the unique situations of (waste)water treatment in each First Nation, the questions become: How can this problem be understood simply? What trends exist nationally? The multiple contexts of what feasibly affect (waste)water systems on-reserve have been given a new form to address all systems simultaneously, one where the cause of risk (water operators) and its solution (certification) are singular.

The Department's Response concludes by stating "[l]egislation will enable the Government of Canada to collaborate with First Nations and other stakeholders to develop a regulatory regime for on-reserve water and wastewater" and that the "Government of Canada is moving forward with water legislation" (AANDC, 2011a). We can only assume that this is referring to Bill S-8, which was introduced six months later. We have seen how the "regulatory regime" unfairly targets treatment plant operation as the site for control/risk to further credentialize the problem, diminishing the ability of First Nations to self-govern (in the eyes of the Federal Government), but also how the premise on which it relies, that treatment plant operators are a large contributor to risk, is a misinterpretation of the data collected. Mascarenhas elaborates:

While many First Nations I interviewed were in favor of more stringent standards and agreed upon practices that protect their drinking water supply, most also felt that this heavy handed use of legislation was an effective means to limit First Nations participation in matters of public health, and provided a means for government to relocate the provision of drinking water expertise firmly in the private sector. (2012, pp. 126-127)

Certainly the retention of private engineering consulting firms to conduct and author the National Assessment with public dollars shows a flow of money to financially support private expertise, but when that same body further advises greater investment in (treatment plant operator) certification, the private sector is not only bolstered but First Nations are even further removed from participating in governing their water resources. This removal of First Nations peoples from a national discussion on water concerns facing them is literally expressed throughout the National Assessment in other ways.

\section{WATER USERS}

Operators, it would seem, are the only humans individualized in the National Assessment. Their individualization, however, is used primarily to assign responsibility for the riskiness of First Nations (waste)water systems in accompanying materials. Nowhere in the National Assessment are people who rely on these water and wastewater systems mentioned, let alone discussed. Divorcing humans from the topic of discussion is evident immediately upon viewing the cover page of the National Assessment: the humans in the photos on the cover have no faces (see Figure 4). They are dehumanized and unrecognizable.

Hard hats obscure all of the photographed persons' facial features except for the scant jawline. Their faces tend to be oriented away from the camera. To be fair, the National Assessment is about water and wastewater systems and not the people who build them, maintain them, operate them, or use them, so it might be out of place to show images featuring humans over the systems. It is bizarre, however, that such a deliberate and conspicuous attempt has been made to remove a human presence from these stock photographs. The problem is not entirely that these sorts of images are being used by an engineering consulting firm for a client (AANDC, in this case). Rather, it 
is that this technical document is the medium through which AANDC has decided to communicate the findings with the public and First Nations who must live with these problems. That this engineering report (documents which typically do not rely explicitly on political, cultural, historical, or social understandings) is the appropriate mechanism for disseminating this information further emphasizes how the problem has been translated into a technical concern. Plus, the images presume that water improvements solely involve hard hatted professionals - that is, engineers and construction workers-completing technical work. Women and Indigenous people are notably underrepresented in these lines of work and they are absent from the cover images. What does this say about who ought to be involved and which roles they play in improving risky (waste)water systems on-reserve?

The National Assessment also excludes water from the discussion. The study isn't even about water and wastewater; it is about the systems that treat water and wastewater. By relying on this

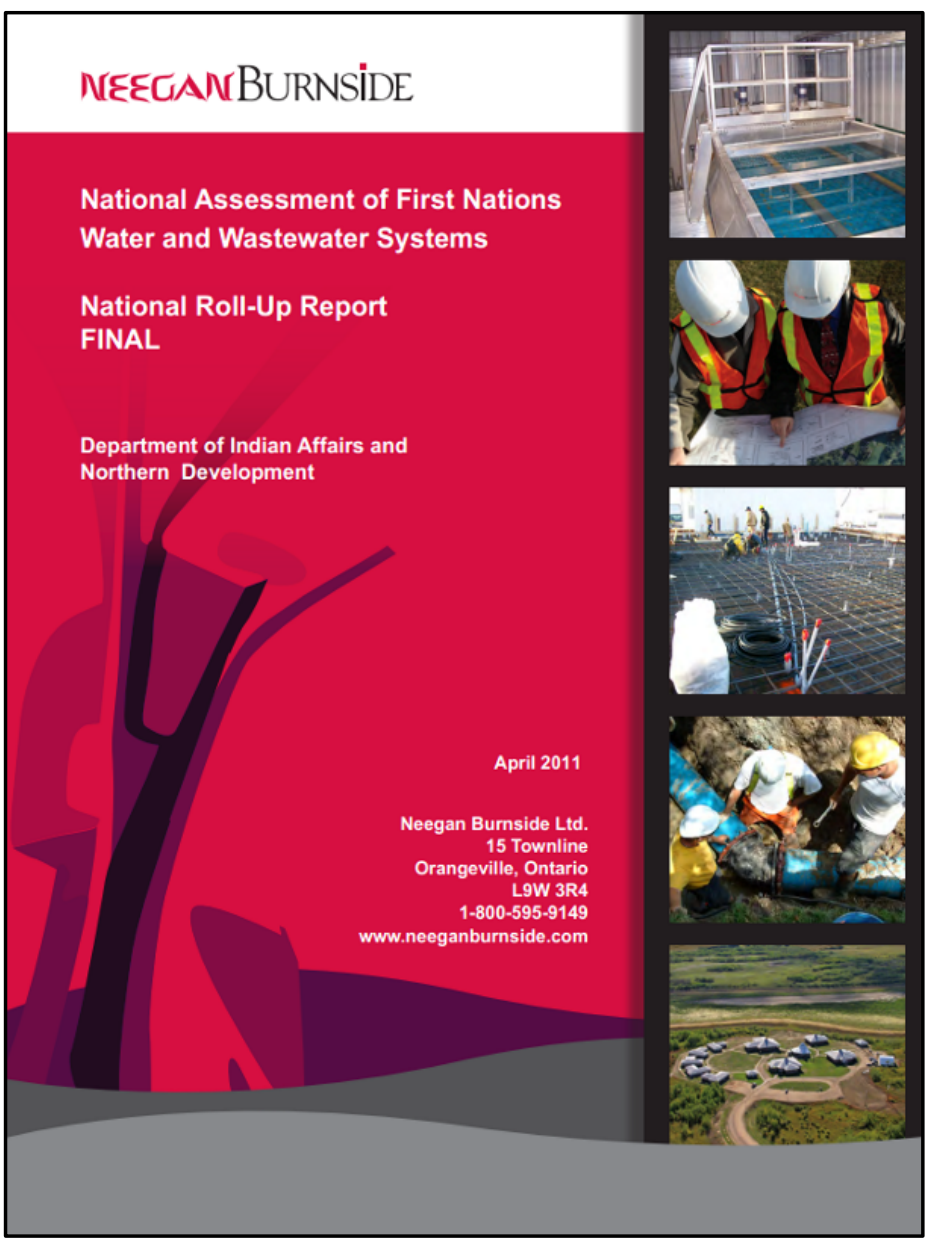

Figure 4. Screen Capture of National Assessment Cover Page (Source: Neegan Burnside Ltd., 2011)

technical engineering approach that focuses on systems or infrastructure, both humans and water are removed from the discussion as though these systems exist independently of either humans or water. Focusing on the technoscientific system ((waste)water systems, in this case) changes the subjects of study (water, people, First Nations communities) into mere parts of a larger system, as explained by Law (2002, pg. 78), and allows the narrator to distribute roles among these parts. Throughout the National Assessment, the real concerns and justifications for conducting the assessment (poor water quality, health problems, decrepit infrastructure) are dissolved. They are now products or expressions of the system (Law, 2002, pg. 78) so that operation, maintenance, and record keeping are what matter. The roles within the system have been successfully narrated and distributed so that water and humans have no purpose, leaving the technical components with all of the focus and importance. This erasure is a recent shift in communicating First Nations water concerns from previous government documentation as discussed below.

Some striking comparisons can be made between the 2011 National Assessment and the 2003 National Assessment of Water and Wastewater Systems in First Nations Communities ${ }^{5}$, which served a

5 The 2003 National Assessment of Water and Wastewater Systems in First Nations Communities Summary Report was not mentioned previously as an accompanying document because it does not really accompany the 2011 National Assessment. I only happened upon it by looking through archived Indian and Northern Affairs Canada webpages. The 2011 National Assessment only references the 2003 National Assessment once, 
similar purpose to the 2011 National Assessment about a decade earlier. First, the 2003 document is actually authored by Indian and Northern Affairs Canada. The 2011 National Assessment is a direct report from a consulting firm to Indian and Northern Affairs Canada.

Second, the third to last paragraph of the 2003 National Assessment reads:

Significant progress has been achieved in improving water quality in First Nation communities over the last 10 years. For example, in 1991, less than 80 percent of on-reserve houses had basic water and sewer services; in 2001, about 98 percent of on-reserve houses had water and 94 percent had sewer services. During this time First Nations have assumed a greater role in the management and delivery of services as part of their move toward selfgovernment. (INAC, 2003, p. 26)

This excerpt reveals a reference to historical data for comparison-something sorely lacking in the 2011 National Assessment-but also contains the word "self-government", a concept missing entirely from the 2011 National Assessment. I do not mean to suggest that the 2003 National Assessment is less paternalistic in what it was attempting to do, but it is a report that used consulting engineers to collect and interpret data that was able to address both historical changes (and improvements) to First Nations (waste)water systems and the reality of self-government for First Nations communities.

The 2003 National Assessment uses the word "Chief" four times, "council" eight times, and "band" four times. The 2011 National Assessment uses "Chief" zero times, "council" twice, and "band" once, despite the fact that the 2011 National Assessment is over twice the length of the 2003 National Assessment. Even if this difference or change is not significant enough to point to a deliberate shift in policy or thinking, it does show how a technical document from 2003 can remain technical while at least acknowledging the political institutions at play; "[i]t is quite common to think that the explanations of engineers are objective, scientific, one-dimensional, lacking in ambiguity, trope or metaphor" (Bucciarelli, 2003, p. 6). Too often engineers express "discomfort at the idea of engaging in activities that might have such an overtly 'political' stance" but express "no reservation about taking an equally political stance in supporting the engineering status quo" (Leydens, Lucena, \& Schneider, 2012, p. 64). Engineering communications must strive to remain objective, neutral, and unbiased, as shown through the political omissions in the National Assessment. But, just because the political institutions involved in planning, execution, and reporting of the 2011 National Assessment are obscured, does not mean they do not exist.

When Beck addresses water pollution specifically, he criticizes the approach of exclusively chemical, biological, and technological understanding, saying that it reinforces the optimism or inevitability of industrialization and can transform into a "discussion of nature without people" (1992, p. 24). This approach not only perpetuates the norm of industrialization (risks are managed rather than avoided) but humans and humanity are excluded. To not inquire about significant cultural, social, and political factors involved in risk hides them from analysis; the social affliction becomes a biological one (Beck, 1992, pp. 25-26). So "what becomes clear in risk discussions are

in the "References" section. No information from the 2003 National Assessment is used to compare the 2011 National Assessment results to, even though the only immediately perceptible difference is that the 2011 National Assessment assessed both public and private systems while the 2003 National Assessment assessed public systems. The 2011 National Assessment evaluated 807 water systems and 532 wastewater systems. The 2003 National Assessment evaluated 740 water systems and 462 wastewater systems. It is curious that not only is the most recent iteration deemed "unprecedented" (AANDC, 2011c) when it really is not, considering it was released less than ten years after the previous evaluation, but it does not use the opportunity to investigate any changes that may have been measured from the previous assessment to show trends in water system risk for First Nations communities. 
the fissures and gaps between scientific and social rationality in dealing with the hazardous potential of civilization" (Beck, 1992, p. 30). These fissures between scientific and social rationality are performed in the National Assessment.

Chronology - Water provides another significant erasure. Canada officially endorsed the United Nations Declaration on the Rights of Indigenous Peoples (UNDRIP) on April 19, 2010. "Article 32" outlines "the right to determine and develop priorities and strategies for the development or use of [Indigenous peoples'] [...] resources" (United Nations, 2008, p. 12) and that

[s]tates shall consult and cooperate in good faith with the [I]ndigenous peoples concerned through their own representative institutions in order to obtain their free and informed consent prior to the approval of any project affecting their lands or territories and other resources, particularly in connection with the development, utilization or exploitation of mineral, water or other resources. (United Nations, 2008, p. 12)

Considering that this declaration defines both water resources management as an Indigenous right and the necessary role that Indigenous peoples play in the approval of water projects, why does its endorsement not appear on the Chronology - Water AANDC webpage? Surely Canada endorsing this declaration is noteworthy enough to appear on the timeline documenting water developments with Indigenous peoples in Canada. This endorsement actually occurred while the National Assessment was being conducted yet no mention of the UNDRIP nor the Indigenous right to manage water resources appears. The administrative and technical aspects supersede the importance of a discussion on Indigenous rights and sovereignty.

\section{END OF PIPE}

These particularly colonial interpretations of data discussed on the AANDC website may not be entirely surprising given the Department's history and mandate. However, engineering practicedespite being a profession that professes objectivity and neutrality and deliberately shies away from taking political positions - can still uphold dominant forms of knowledge through its technical documentation. In the case of the National Assessment, the denigration of non-professional expertise and authority reproduces Canada's racial formations.

I have shown that this sort of documentation-particularly the form in which it is presented to the public-is in fact, not all that technical. The way in which the information is shared tries to comfortably hide it from scrutiny under the guise of technical expertise with the warning that "[t]he National Assessment results provide a substantial amount of information, much of which is fairly complicated and technical in nature" to dissuade alternative interpretations. Not only should the presentation and interpretation of the data collected be done in a way to promote public consumption, but readers should be encouraged to undertake this sort of examination lest we continue to believe these documents' myths of apoliticism.

The National Assessment of First Nations Water and Wastewater Systems, as a technical engineering report, reflects political ideologies. The National Assessment, in both its process and content, is consistent with current federal legislation and exercises of colonial authority. The practice of conducting an assessment of First Nations (waste)water systems shows no acknowledgement of First Nations autonomy in the management of their own water resources. Further, the National Assessment reinforces a system in which First Nations communities are defined to be risky via an external system to which they must appeal for funding to become less risky. Since funding is directed to where an identified problem exists, the ability for First Nations to even demonstrate self-governance of water resources is lost. Last, the reliance on a technical document to communicate the findings exploits indirect language and a lack of human presence to continue to address concerns for water and First Nations peoples without having to discuss either water or 
First Nations peoples directly. This facilitates a national discussion, or lack of discussion rather, on the denial of Indigenous water rights and Indigenous governance of water resources.

\section{DOWNSTREAM}

Over a year after our first meeting, I see Roxane, this time at an evening event on campus celebrating Indigenous authors. We recognize each other, she introduces her daughters who don't seem too interested in making my acquaintance, and I sit with her family at the back of the lecture hall. We exchange a few whispered words during the readings but we sit in silence mostly, listening to the stories. I reflect on some questions I can ask her when the event has ended but before that can happen, Roxane stands up with her daughters and explains that they have to leave early. I try to reassure her (and myself) that I'm still considering our conversation from a year ago, reflecting on the things she had shared with me, and that we will discuss this another time. We hug goodbye and she tells me to send her an email.

Engineers pride themselves on their ability to "solve problems" using their knowledge of scientific laws and technological innovation to do so, without having to mess with politics. But which political goals can be served when certain problems arrive at the engineer's desktop predefined? Or what implications can arise from engineering work that goes critically unexamined? History, culture, and community can certainly complicate some problems, but in excluding relevant system components, in stripping context from reality, in reducing multiplicity to singularity, solutions will remain elusive. And maybe there is a role for engineers and engineering in addressing these types of problems. Maybe it's just not up to engineers to decide. There are others setting the dialogue.

\section{REFERENCES}

Aboriginal Affairs and Northern Development Canada. (2011a). Department's response to the National Assessment of First Nations Water and Wastewater Systems. Retrieved from http://www.aadnc-aandc.gc.ca/eng/1314383237592/1314383364994.

Aboriginal Affairs and Northern Development Canada. (2011b). Fact sheet - Risk assessment of water and wastewater systems in First Nations communities. Retrieved from https://www.aadnc-aandc.gc.ca/eng/1313687144247/1313687434335.

Aboriginal Affairs and Northern Development Canada. (2011c). Fact sheet - The results of the National Assessment of First Nations Water and Wastewater Systems. Retrieved from https://www.aadnc-aandc.gc.ca/eng/1313762701121/1313762778061.

Aboriginal Affairs and Northern Development Canada. (2011d). Fact sheet - Understanding the results of the National Assessment. Retrieved from http://www.aadnc-aandc.gc.ca/eng/1313683655131/1313684039612.

Aboriginal Affairs and Northern Development Canada. (2012). National assessment of First Nations water and wastewater systems - 2009-2011. Retrieved from https://www.aadnc-aandc.gc.ca/eng/1313426883501/1313426958782.

Aboriginal Affairs and Northern Development Canada. (2013). Chronology - Water. Retrieved from http://www.aadnc-aandc.gc.ca/eng/1308332537951/1308332754073.

Assembly of First Nations. (2011). AFN responds to the National Assessment of First Nation Water and Wastewater System Report. Retrieved from http://www.afn.ca/index.php/en/news-media/latestnews/afn-responds-to-the-national-assessment-of-first-nation-water-and-wast.

Bucciarelli, L. (2003). Engineering philosophy. Delft: Delft University Press.

Craft, A. (2013). Re: Bill S-8, Safe drinking water for First Nations act. Submission to Standing Committee on Aboriginal Affairs and Northern Development via Chris Warkentin, Chair. Canadian Bar Association. Retrieved from http://www.afn.ca/uploads/files/water/bar-assoc-s8.pdf. 
Foucault, M. (1980). Power/Knowledge-Selected interviews and other writings 1972-1977. C. Gordeon (ed.). Brighton: Harvester Press.

General Assembly of the United Nations. (2008). United Nations declaration on the rights of Indigenous peoples. Retrieved from http://www.un.org/esa/socdev/unpfii/documents/DRIPS_en.pdf.

Haraway, D. (1988). Situated knowledges: The science question in feminism and the privilege of partial perspective. Feminist Studies, 14.3, pp. 575-599.

Hunt, S. (2014). Ontologies of indigeneity: The politics of embodying a concept. Cultural Geographies, 21.1, pp. $27-32$.

Indian and Northern Affairs Canada. (2003). National assessment of water and wastewater systems in First Nations communities, summary report. Retrieved from http://www.aadnc-aandc.gc.ca/DAM/DAM-INTERHQ/STAGING/texte-text/watw_1100100016374_eng.pdf.

LaDuke, W. (1999). All our relations: Native struggles for land and life. Cambridge: South End Press.

Latour, B. (1987). Science in action: How to follow scientists and engineers through society. Cambridge: Harvard University Press.

Law, J. (2002). Aircraft stories: Decentering the object in technoscience. Durham and London: Duke University Press.

Leydens, J. A., Lucena, J. C., \& Schneider, J. (2012). Are engineering and social justice (in)commensurable? A theoretical exploration of macro-sociological frameworks. International Journal of Engineering, Social Justice, and Peace, 1.1, pp. 63-82.

Mascarenhas, M. (2012). Where the waters divide: Neoliberalism, white privilege, and environmental racism in Canada. Lanham: Lexington Books.

Neegan Burnside Ltd. (2011). National assessment of First Nations water and wastewater systems: National roll-up report. Retrieved from http://www.aadnc-aandc.gc.ca/DAM/DAM-INTER-HQ/STAGING/textetext/enr_wtr_nawws_rurnat_rurnat_1313761126676_eng.pdf.

Open Parliament. (2014). Bill S-8 (Historical) safe drinking water for First Nations act: House Debate. Retrieved from https://openparliament.ca/bills/41-1/S-8/?singlepage=1.

Potts, K. \& Brown, L. (2005). Becoming an anti-oppressive researcher. In L. Brown \& S. Strega (Eds.), Research as resistance: Critical, Indigenous, and anti-oppressive approaches (pp. 255-286). Toronto: Canadian Scholars' Press.

Senate of Canada. (2012). Bill S-8: An act respecting the safety of drinking water on First Nation lands. Retrieved from http://www.parl.gc.ca/HousePublications/Publication.aspx?Docid=5409485\&file=4.

Todd, Z. (2014). An Indigenous feminist's take on the Ontological Turn: 'Ontology' is just another word for colonialism. Retrieved from https://zoeandthecity.wordpress.com/2014/10/24/an-indigenousfeminists-take-on-the-ontological-turn-ontology-is-just-another-word-for-colonialism/.

Watts, V. (2013). Indigenous place-thought and agency amongst humans and non-humans (First Woman and Sky Woman go on a European world tour!) Decolonization: Indigeneity, Education \& Society, 2.1, pp. 2034. 